\title{
REDUCING DOMESTIC FOOD WASTE BY FREEZING AT HOME
}

\author{
T. BROWN ${ }^{1}$, N.A. HIPPS ${ }^{2}$, S. EASTEAL ${ }^{3}$, A. PARRY ${ }^{3}$ AND J.A. EVANS ${ }^{1}$ \\ ${ }^{1}$ Refrigeration Developments and Testing Ltd \& London South Bank University, \\ Langford, North Somerset, BS40 5DU, UK. Fax +44 117 9289314, Email tim.brown@rdandt.co.uk \\ ${ }^{2}$ East Malling Research, UK \\ ${ }^{3}$ Waste \& Resources Action Programme (WRAP), UK
}

Keywords: Food Waste Reduction Domestic Freezing

\begin{abstract}
It is estimated that over 630,000 tonnes of 'freezable' food, worth up to $£ 2.3$ billion, are thrown away by UK consumers each year due to having passed labelled 'use by' dates or being perceived to have spoiled. Much of this food could instead have been frozen for later consumption, but research has shown that consumers are often uncertain about suitability of products for home freezing. A two-part study was therefore undertaken, starting with a literature and internet-based information review which found that although the majority of products are reported as suitable for home freezing, there is conflicting advice on some products and also marked differences between reported storage lives. As increased use of freezers would lead to greater energy consumption, the review was followed by an experimental assessment which found that the value and carbon dioxide emissions associated with the saved food far outweighed those associated with the additional energy.
\end{abstract}

\section{INTRODUCTION}

Research has identified that consumers in the UK throw away around 4.2 million tonnes of avoidable food waste each year (WRAP, 2013a). Over 630,000 tonnes of this, worth around $£ 2.3$ billion, is 'freezable' food (bread, meat etc.) that could have been frozen before it reached this point and eaten at a later date. Consumer research has shown that one of the major reasons why such products are not frozen is confusion about whether they are suitable for freezing and lack of knowledge of how best to freeze them to maximise their quality (WRAP, 2010).

Scientific studies related to home freezing and domestic storage rather than commercial production and cold storage of frozen food might help to address this issue, but such studies are extremely scarce. There is however considerable advice and guidance on internet websites maintained by a wide variety of organisations and individuals. A literature and information review was therefore undertaken to assess the suitability for freezing of a range of different foods, and to provide information on freezing techniques and storage times.

While greater use of home freezing could lead to reduced food waste, it was recognised that it will also have an impact on the amounts of energy used by domestic freezers (both to freeze food and because doors are opened more frequently). Published data on this energy impact could not be located. An experiment was therefore devised to enable comparison of the costs and embodied equivalent carbon dioxide emissions $\left(\mathrm{CO}_{2} \mathrm{e}\right)$ associated with a typical selection of food saved by domestic freezing and the additional energy used by the freezer. 


\section{METHOD}

\subsection{Literature and information review}

An initial literature and information review was undertaken to combine relevant data from the limited numbers of peer-reviewed publications (scientific journal papers and textbooks) and commercial sources (industry guidance notes and trade press articles) with advice and data from online sources. The online sources were chosen with caution, but included advice websites maintained by government and commercial bodies, and where appropriate sites maintained by private individuals. The review concentrated on assessing the quality of available data on home freezing suitability and frozen storage life of 41 chosen food products.

The products chosen were sliced / unsliced bread, rolls and baguettes, world breads, pizza, fruit juice, fruit smoothies, eggs, quiche, oily fish, white fish, prawns, fruit frozen in current form, fruit treated before freezing, cooked pasta, cooked rice, mashed potato, pasta meals, rice meals, ready meals, meat pie, soup, bacon, beef, chicken / turkey, lamb, pork, sausages (raw), home cooked meat joint, cooked sliced ham, sausages (cooked), cream, hard cheese, milk, soft cheeses, yoghurt, leftover cooked vegetables, vegetables (sauced / pureed, raw), vegetables (blanched, raw), vegetables (whole / chopped, raw), fruit cake and sponge cake.

Where explicit comments on suitability for freezing of a particular product were not found, the presence of reported storage lives was taken to imply suitability. Where comments on suitability were found, the assessment determined whether it was reported that a product:

- can be successfully frozen with little cellular damage (and minimal impact on texture and structure);

- can be frozen but with cellular damage (and significant degradation to texture and structure);

- can be frozen but with resultant changes to other quality traits e.g. flavour, odour or appearance;

- cannot be frozen successfully.

Using the initial assessment data, 12 products were selected for more extensive review. The selection was based on several factors: the likely impact on reducing household food waste if freezing was more widely practised; the need for information required by consumers to allow more widespread freezing, and; the availability of guidance related to home freezing, which food manufacturers and retailers might usefully employ on food packaging. The 12 products were bread, pork (cooked sliced ham, bacon, raw and cooked sausage), vegetables, fruit, pasta meals (home-made), rice meals (home-made), chilled ready meals, milk, store-bought yoghurt, fruit juice, ambient cooking sauces and meat joints (raw and cooked).

For these products there were considerable differences in suggested storage lives. The results were therefore analysed with the aim of deriving 'consensus' values for the reported storage lives for each selected product. In addition, the review focussed on possible reasons for storage life variability, including:

- initial product quality and age;

- storage before freezing and handling procedures;

- packaging;

- freezing method and rate of freezing;

- frozen storage conditions;

- thawing method and rate;

- the need for cooking after thawing.

Where such reasons were stated, they were recorded, but often no reasons were given. In these cases only the suggested storage lives were recorded. Much of the guidance and advice was general to all products, and this was reported in a comprehensive general section separately from the specific product material. 


\subsection{Assessment of energy impact}

An example of the UK best selling stand-alone upright freezer in 2010, the A-class Beko TZDA504FW, with a manufacturer's stated energy consumption of $262 \mathrm{kWh}$ per annum and a net storage volume of 157 litres, was purchased. It was installed in a controlled environment test room running at $20^{\circ} \mathrm{C} \pm 0.5^{\circ} \mathrm{C}$, which aligns with the average kitchen temperature found in a survey conducted by James and Evans (1992). A standalone freezer was chosen rather than a fridge-freezer because the energy impact is more direct and therefore measurable. This is because most fridge-freezers are controlled by a single thermostat in the fridge section not the freezer section, so the effect of adding warm food to the freezer takes longer to impact on the energy used, and the analysis of the impact is complicated by temperature behaviour in the fridge as well as the freezer section.

The freezer was loaded to approximately $3 / 4$ full in each compartment with a selection of typical frozen food items which acted as a base load. T-type thermocouples were positioned to measure air and product temperatures at the centres of top, middle and bottom sections of the freezer. The freezer was connected to a stabilised power supply via a power meter (Northern Design, UK). All temperature and power data were recorded at 1-minute intervals using a data logging system (Measurement Systems, UK) to accuracies of \pm $0.5^{\circ} \mathrm{C}$ and $\pm 2 \%$ respectively. A purpose-built door opening mechanism was attached to the freezer to automatically simulate a domestic door opening regime. The regime was designed during similar commercial freezer testing to mimic two one-hour periods of opening per day, one at breakfast time and one at evening meal time. During each of these periods the door was opened every 10 minutes for 15 second intervals to an open angle of greater than 60 degrees.

The appliance was allowed to achieve stable operation at its default (as supplied) thermostat setting, but was then adjusted to achieve an approximate mean frozen food temperature of $-16.7^{\circ} \mathrm{C}\left( \pm 1^{\circ} \mathrm{C}\right)$ to match the European average freezer temperature defined in the preparation report for Energy-using Products (Faberi, 2007). As the freezer had an automatic on-demand defrost, which was initiated at varying intervals of up to 5 days apart, temperatures and power were recorded at each thermostat setting until at least a full day of stable operation had been achieved after defrost.

To assess the impact of adding a mixture of chilled and ambient food to the freezer, four typical products were added:

- cooked beef lasagne (732g portion from a $1.5 \mathrm{~kg}$ family pack) in an air tight container, cooled to approximately $20^{\circ} \mathrm{C}$;

- cooked beef cottage pie ready meal (415g portion from an $800 \mathrm{~g}$ pack) in original packaging of plastic tray, cooled to approximately $20^{\circ} \mathrm{C}$;

- raw chicken breasts (638g, two out of a pack of four) in a freezer bag, at fridge temperature of approximately $7^{\circ} \mathrm{C}$;

- half a loaf of white sliced bread in original packaging $(517 \mathrm{~g})$, at temperature of approximately $7^{\circ} \mathrm{C}$.

The addition of the food to the freezer was timed to be half way between two defrosts. The door opening mechanism was stopped and the freezer door manually opened to an angle of $90^{\circ}$. One of the portions of food was added at the centre of the top surface of food in each of the drawers within the freezer and thermocouples positioned in the centre and at the surface of each portion. The door was then closed and the automatic door opening mechanism re-started. The time required to add the food was approximately 2 minutes in total. The temperature and power data were again recorded until at least a full day of stable operation had been achieved after defrost to allow comparison with the stable operating period.

The additional heat load on a freezer during food addition comes from a combination of heat from the warm food added and heat gained through having an additional (and relatively lengthy) door opening. To 
determine the relative amounts of these heat loads, a further consecutive trial was undertaken. A period of stable operation was monitored to ensure that temperatures were equivalent to those in the previous stable period i.e. the freezer had not become iced due to insufficient defrosting. The door opening part of the food addition trial was then repeated but this time without adding the food.

\section{RESULTS}

\subsection{Initial assessment}

For the initial range of 41 products, information on suitability for freezing, practical storage life at $-18^{\circ} \mathrm{C}$ and advice on pre-freezing treatments and handling was extracted from 71 reputable online sources, 20 peerreviewed scientific journal papers and 9 reference books and guidance reports (including some previous WRAP publications). Most of these references covered multiple products. As might be expected the availability of data varied considerably between products, with some having multiple sources of comprehensive data and others having no sources at all. Where multiple sources were found, the advice on freezing and the values for PSL were not necessarily in agreement. Examples of this are shown in Figure 1, which presents PSLs at $-18^{\circ} \mathrm{C}$ for frozen loaves of bread, and Figure 2, which presents PSLs at $-18^{\circ} \mathrm{C}$ for frozen raw and cooked pork products.

Continuing with bread as an example, the majority of sources reported only one value for PSL but several gave ranges e.g. 3 to 6 months, represented on the chart by connected maximum and minimum values. Such variability could result from various factors such as

- Product: type of bread, ingredient variability, packaging materials and seal;

- Equipment: freezing rate, different patterns of fluctuations in storage temperature;

- Methods of assessment: basis of assessment (i.e. which quality traits were assessed), measurement techniques and equipment, etc.

Reasons for some of the outlying values were apparent. The shortest live were reported for bread stored in normal plastic shop packaging with tape seals, while longer lives were reported for bread in more robust freezer packaging with greater moisture and oxygen impermeability and air-tight seals. However, such reasons were not always apparent and in many cases a full description of all of the above factors was not available. In these circumstances a decision to include or exclude certain sources would have been subjective and it was decided to report all values but then to determine an average 'consensus' value. In the case of loaves of bread, this value was taken to be 3 months.

The majority of the products were found to be suitable for home freezing, with just soft cheeses (cottage, Philadelphia, brie etc.) being generally unsuitable for freezing and conflicting advice existing on the suitability of freezing cream and cream-based sauces. Impacts on quality due to freezing and associated effects on suitability for freezing were considered for all products in the literature review, and only in the above examples, i.e. soft cheeses and cream products, were such impacts stated to render the products unsuitable for freezing. It was also deemed important to consider whether the freezing method and freezing rate (i.e. commercial versus domestic) affects quality to the extent that some foods are suitable for commercial freezing but not for home freezing. No specific examples of products which were not suitable for freezing at slower rates were found, although in general it is advisable to organise domestic freezing in such a way that freezing times are not excessively long. This includes avoidance of large, thick or stacked packages and use of fast freeze functions or lower freezer temperatures during freezing.

Although agreement on suitability was good, there were however some marked differences between quoted Practical Storage Lives (PSLs) for seemingly similar products. Detailed results for all 41 products and their sources are presented in the project report (WRAP, 2012), together with general advice and guidance for home freezing, and specific product advice. 


\subsection{In-depth review for 12 selected products}

For the 12 selected products, all were either explicitly reported to be suitable for freezing or if PSLs were suggested it was assumed that freezing with little or no detriment to quality was possible. For each of these products, data were compiled on all reported PSLs at $-18^{\circ} \mathrm{C}$ (which is a temperature widely used in experimental trials and for which there are therefore likely to be more abundant data).

The numbers of references for each of the 12 products varied as follows: bread (14), pork products (19), vegetables (26), fruit (19), home-cooked pasta meals (5), home-cooked rice meals (3), chilled ready meals ( 0 , although there is a prevalence of on-pack freezing guidance), milk (5), yoghurt (6), fruit juice (5), ambient cooking sauces ( 0 , but there is some on-pack guidance and similarity to chilled sauces) and cooked and raw meat joints (40). A summary of the product specific findings is shown in Table 1, and full detailed results are given in the project report (WRAP, 2012).

\subsection{Energy impact of increased freezer use}

Temperatures in domestic refrigerators and freezers are controlled by thermostats which turn the refrigeration system (compressor) on when temperatures are too warm and off when temperatures are satisfactory. The result is a cyclic on/off operation during which temperatures repeatedly pull down when the compressor is turned on and then rise again when the compressor is turned off. When the compressor is running, the power is generally very similar regardless of the heat load, as the power of the compressor varies little while switched on. However, under greater heat loads, it is the length of time for which the compressor runs which increases overall energy consumption.

To determine the appropriate analysis periods for pull-down after loading and for stable operation, average air temperatures were calculated using the measurements from the three thermocouples positioned in the top, middle and bottom sections of the freezer. Averages were also calculated for the temperatures measured in the centres and at the surfaces of the four added food products. Figure 3 shows these average temperatures during the period following addition of the warm foods listed in Section 2.2.

Air temperatures rose initially due to the added heat loads from the additional door opening and the warm food added. By the start of the second 24 hour period, the freezing process was complete and air temperatures returned to values which were similar to those in stable periods. During the third 24 hour period the freezer initiated a defrost, causing a slight rise in the average temperatures, although these quickly dropped back to stable values. The period following the additional door opening without added food showed a similar pattern, but with less of an impact on temperatures in the first 24 hours. To make sure the freezer was not progressively icing up (which could affect its performance) the lengths of defrosts in each section of the trials were checked and found to be unaffected by the warm food or additional door opening, and temperatures recovered to the same values after defrosts. Analysis periods of 24 hours were therefore chosen for assessing additional energy used after adding food or opening the door without adding food.

As described above, greater heat loads on the freezer, such as those from increased door opening or addition of warm food, will result in the compressor having to run for longer periods. This is reflected in the run times, which are the percentage of time for which the compressor ran on each day of measurement. Table 2 shows that opening the door increased the run time by a small amount ( 3.1 percentage points), and opening the door and adding warm food increased the run time by a greater amount ( 8.2 percentage points). For clarity it should be mentioned that as the tests were undertaken in sequential order, the increase for 'adding food and door opening' and then for 'door opening only' were calculated based on the immediately preceding stable periods, not always on the initial stable period.

As expected, the energy consumed by the freezer closely aligned with its run times. For example when the listed warm food items were added, the power consumption rose by $26.7 \%$ of its stable value over the first 
24 hours, and the run time increased by $27.3 \%$ of its stable value. When the additional door opening only was applied these increases were $9.9 \%$ and $10.6 \%$ respectively. The extra average power from door opening and warm food was $6.4 \mathrm{~W}$ while that from door opening only was $2.4 \mathrm{~W}$. Converting the power values to the units of energy paid for by consumers $(\mathrm{kWh})$ gives the figures shown in Table 2 for each 24 hour period. There were slight differences in the stable energy consumptions before and after the adding food and door opening tests, but these were less than one percentage point compared with the initial value and were most likely due to measurement accuracy.

To check the validity of the power measurements, the theoretical heat load required to be removed from the food was calculated. For each food, the supplier's stated physical composition data (protein, carbohydrate, fat, minerals and water) were entered into the COSTHERM property prediction program (Miles, Van Beek and Veerkamp, 1983) and the enthalpy differences between the start and end of the freezing process were determined. For the lasagne, bread, chicken and cottage pie these enthalpy differences were 325.7, 153.4, 240.7 and $321.5{\mathrm{~kJ} . \mathrm{kg}^{-1}}^{-1}$ respectively, which equated to a total of $604.7 \mathrm{~kJ}$ for all of the food. Averaged over the test period of 24 hours in the same way as the power measurement, this was equivalent to a heat load of 7.0W. To convert this to refrigeration system power, the Coefficient of Performance (COP) of the compressor was taken from the manufacturer's performance data (ACC, 2003). Assuming 10K temperature differences for the evaporator and condenser (i.e. evaporation at $-28^{\circ} \mathrm{C}$ and condensation at $30^{\circ} \mathrm{C}$ ), a COP of approximately 1.8 is indicated, which would convert the calculated product heat load of $7.0 \mathrm{~W}$ to a compressor power of $3.9 \mathrm{~W}$. This compares closely with the measured power increase of $4.0 \mathrm{~W}$ for the food alone.

To extend the check to the compressor run-time values, the same enthalpy differences and COP were used to assess the measured increases in power consumption and percentage run time due only to the added food. The refrigeration duty of the compressor with a power consumption of $80 \mathrm{~W}$ and a COP of 1.8 was $144 \mathrm{~W}$. The theoretically derived added heat $(604.7 \mathrm{~kJ})$ would therefore take 1.16 hours to remove. The stable runtime was 7.20 hours ( $30.0 \%$ in a 24 hour period), so with the heat load from the food added the run-time would increase to 8.36 hours (34.8\%). Again, the increase compares closely with the measured increase in run-time, which was $4.9 \%$ just for adding the food.

More detailed results for the energy impact assessment are presented in a second project report (WRAP, 2013b).

3.4 Comparison of costs and emissions associated with the added food and the additional energy

To allow comparison of the costs and associated carbon dioxide emissions of the food saved and the increased energy, the following calculations were applied:

- The increase in energy due to food addition was $6.4 \mathrm{~W} * 24 / 1000=0.154 \mathrm{kWh}$.

- This can be split into the increase caused by adding the warm food $(4.0 \mathrm{~W}$ or $0.096 \mathrm{kWh}$, equivalent to $62.3 \%$ ) and that caused by the door opening ( $2.4 \mathrm{~W}$ or $0.058 \mathrm{kWh}$, equivalent to $37.7 \%)$.

- The cost of this extra energy was $0.154 \mathrm{kWh} * £ 0.1155$ per $\mathrm{kWh}$ (average UK domestic price per unit: source DECC, 2011) $=£ 0.018$. The purchase cost of the food items in the test was $£ 5.36$, giving a ratio of over 1:300 in favour of saving the food.

- The $\mathrm{CO}_{2} \mathrm{e}$ emissions associated with the extra energy were $0.154 \mathrm{kWh} * 0.44548 \mathrm{~kg} \mathrm{CO}_{2} \mathrm{e} / \mathrm{kWh}$ (Carbon Trust, 2013 - please note this is an updated conversion factor compared to that used in project report WRAP, 2013b) $=0.068 \mathrm{~kg} \mathrm{CO}_{2}$.

- The $\mathrm{CO}_{2} \mathrm{e}$ associated with the food saved was $2.302 \mathrm{~kg} * 3.8 \mathrm{~kg} \mathrm{CO}_{2} \mathrm{e} / \mathrm{kg}$ food (estimate of average $\mathrm{CO}_{2} \mathrm{e}$ associated with wasted food, WRAP $2009-$ Appendix E) $=8.75 \mathrm{~kg} \mathrm{CO}_{2} \mathrm{e}$. This gives a ratio of over 1:100 in favour of saving the food. 


\section{DISCUSSION}

The review of literature and online information found that the majority of foods are reported as being suitable for home freezing. A wide range of information sources were reviewed, with extensive and consistent information being available for some products. The lack of information for other products suggests that there are real benefits to ensuring that consumers have access to good freezing guidance either through publicity activities or in-store notices and on-pack labelling. Manufacturers are encouraged to carry out product freezing trials to help inform advice given on their products, and to their customers (for further guidance, see for example WRAP website www.wrap.org.uk/groceryresearch).

There was striking variability in reported storage lives for some of the products, which may be due to a variety of factors. Generally, storage at lower temperatures will achieve longer storage life. In the review $-18^{\circ} \mathrm{C}$ (for which there were most abundant data) was considered to approximate to temperatures achieved in home freezers. Many of the data sources referred to commercial freezing rather than home freezing, which is likely to be slower than an industrial process. Domestic freezers may also struggle to remove heat quickly enough if loaded with too many items of warm food. Nevertheless, in general the freezing rates achieved by domestic freezers are perfectly acceptable on quality and safety grounds.

Much of the variability in reported PSLs for individual products is likely to be due to a variety of product, processing and packaging (PPP) factors. Product factors include variations in raw material between samples from different breeds or cultivars, time between harvest or slaughter and initial chilling, initial quality of samples (ripeness, cleanliness and physical damage), handling during harvest/slaughter, transport and processing, and seasonality of the product. To have maximum shelf life, the food should have good initial microbiological, physical and sensory qualities and undergo as few higher temperature processes as possible (apart from some decontamination procedures such as pasteurisation).

Processing factors include cutting, slicing and dicing, which can increase enzymatic activity and distribute and accelerate growth of micro-organisms. Mincing can also reduce shelf life in a similar way by spreading bacteria from the surfaces of the meat to the inner tissues and creating greater exposed surface area, and also by adding heat during the mincing process. Addition of fat to mince can reduce storage life by increasing exposed fat surfaces which are susceptible to oxidation and rancidity. To help minimise this, a high grade wrapping material, which has the ability to exclude air, must be used to wrap the product. Additives such as antioxidants and many spices (which contain antioxidants) can be used to extend shelf life. Oxygen scavenging compounds, such as ascorbic acid, reduce the availability of oxygen for oxidation reactions and slow down the onset of rancidity. However, some additives e.g. salt, are oxidising agents and can act to promote oxidation and rancidity.

Packaging has a direct effect on storage life of frozen foods, especially those with high fat contents. It can also, in extreme cases, indirectly affect storage life due to substantially increasing the freezing time. Wrapping in a tightly fitting pack, with a low water and oxygen permeability (such as a vacuum pack) can more than double the storage life of a meat product. Waterproof packing also helps to prevent freezer burn and tight packing helps to prevent ice build-up within the pack.

It was apparent during the review that there is a relatively high incidence of online advice originating from American and Canadian websites. An important question is whether the guidance given by such sources in one country is equally applicable in another. As food production methods, retail distribution chains and domestic freezer equipment in areas such as Europe are similar to those in North America, it is probable that the advice is generally applicable to these areas. Care should however still be taken to ensure that advice relates to similar products with similar packaging. 
Experimental assessment of the energy impact of increased home freezing showed that the potential cost and $\mathrm{CO}_{2} \mathrm{e}$ savings associated with the saved food waste far outweighed the cost and $\mathrm{CO}_{2} \mathrm{e}$ associated with the increased energy use. The exact balance of these figures is dependant among other things on the particular foods chosen for the test, as more or less expensive and energy intensive foods would give a different result. However, such differences would not reverse the balance of food over energy. The analysis does of course assume that the food is subsequently consumed and not simply disposed of later. However, even if only one item out of the four in the experiment were consumed, the balance would still be in favour of freezing. In the other extreme, if all of the 630,000 tonnes of 'freezable' food wasted each year in the UK was instead frozen and subsequently eaten, the net value saved would be close to the value of the food (estimated at $£ 2.3$ billion) and the net saving in associated emissions would be over 2.4 million tonnes $\mathrm{CO}_{2} \mathrm{e}$.

The measured energy results would have been influenced by a range of factors, such as freezer and ambient temperature, food weight added and its temperature, increased door openings (also compounded by high ambient humidity), energy class level etc. However, the freezer and ambient conditions were chosen to represent average conditions from UK and European surveys, and the door opening regime was designed to be typical of domestic use. In addition, the best-selling appliance chosen was typical of the most commonly found energy class level for new freezers. That being the case, the results probably reflect an average energy impact rather than a maximum impact, but as with the types of food discussed above, it is not expected that reasonable changes to any of these factors would reverse the balance of saved food over energy.

There is another potential energy impact associated with frozen rather than chilled food; that from thawing, reheating and cooking. If food is cooked directly from frozen, the energy used by the cooking equipment will increase. However, as mentioned in the literature review results, for many foods it is advised to thaw the food first, mostly in the refrigerator (which would actually reduce the energy used by the refrigerator) or sometimes in ambient air (which would have very little if any energy impact). In the absence of statistics on thawing methods it was assumed that on balance there would be no overall increase in energy from this source.

The validity check on the power increase measured for the food alone showed good agreement between experimental and theoretically derived values. A similar exercise on the impact of door opening was considered based on previously published work, but although studies on the effect of freezer door openings are numerous, many relate to commercial size cold stores and freezers. For those which relate to domestic appliances, comparison of results with the current study is complicated by differences in ambient conditions, use of fridge-freezers (where the impact on the freezer section alone is masked), by presentation of the total impact of door opening regimes such as 15 openings in 24 hours rather than a single additional opening, and by differences in loading and use or non-use of enclosed drawers (which result in different infiltration rates). A direct comparison was therefore not possible. In more general terms however, as would be expected, similar increased energy consumption due to door opening activity has been confirmed (see for example Gin, Farid and Basal, 2012 and Liu, Chan and Lin, 2004).

Although it is recognised that the experimental assessment was limited in scope, having been undertaken with only one appliance, the balance of the costs (over 300 times) and associated emissions (over 100 times) was so highly in favour of saving food that it would be unlikely to be reversed for other appliances. Nevertheless, a useful expansion of the assessment might be to include fridge-freezers and possibly older, less efficient types of freezer.

\section{CONCLUSIONS}

The vast majority of food products can be successfully frozen with little or no damage to quality. Experimental assessment showed that savings in cost and associated emissions resulting from home freezing 
and later consumption of food rather than disposal can be achieved with negligible increases in energy cost and emissions. Consumers should therefore be encouraged to use their freezers in this way to reduce waste. To help them do so, the challenge to the food and retail industries is to improve the availability of freezing guidance in suitable literature and online advice, as well as in in-store information and on-pack labelling.

\section{ACKNOWLEDGMENTS}

The research reported in this paper was funded by Waste \& Resources Action Programme (WRAP, UK, http://www.wrap.org.uk).

\section{REFERENCES}

1. ACC (2003), Performance data for HTK80AA compressor. Available online at www.the-accgroup.com/ACCDocs/16.pdf, accessed December 2013.

2. Carbon Trust (2013), Conversion factors - Energy and carbon conversions 2013 update, available online at http://www.carbontrust.com/news/2013/09/conversion-factors-guide-updated-to-use2013-emission-factors accessed November 2013.

3. DECC (2011), UK energy prices, available online at http://www.decc.gov.uk, accessed September 2012.

4. Faberi, S. (2007), Preparatory Studies for Eco-design Requirements of EuPs; LOT 13. Domestic refrigerators and freezers, Final Report.

5. Gin B., Farid M.M. and Bansal P.K. (2010), Effect of door opening and defrost cycle on a freezer with phase change panels, Energy Conversion and Management, 51, pp2698-2706.

6. James S.J. and Evans J.A. (1992), Consumer handling of chilled foods: temperature performance, Int. J. Refrig., 15, pp299-306.

7. Liu D.-Y., Chang W.-R. and Lin J.-Y. (2004), Performance comparison with effect of door opening on variable and fixed frequency refrigerators/freezers, Applied Thermal Engineering, 24, pp22812292.

8. Miles C.A., Van Beek G., and Veerkamp C.H. (1983), Calculation of thermophysical properties of foods. In Jowitt R. et al. (Eds.), Physical properties of foods, Applied Science Publishers, London \& New York, pp269-312.

9. WRAP (2010), Understanding consumer use of the freezer, report available online at http://www.wrap.org.uk/content/understanding-consumer-use-freezer, accessed July 2013.

10. WRAP (2012), Review of literature about freezing food at home, report available online at http://www.wrap.org.uk/content/review-literature-about-freezing-food-home, accessed November 2013.

11. WRAP (2013a), Household Food and Drink Waste in the United Kingdom 2012, ISBN: 978-184405-458-9.

12. WRAP (2013b), Impact of more effective use of the fridge and freezer, report available online at http://www.wrap.org.uk/content/impact-more-effective-use-fridge-and-freezer, accessed November 2013. 


\begin{tabular}{|c|c|c|c|c|}
\hline Product & $\begin{array}{c}\text { Availability of } \\
\text { info }\end{array}$ & $\begin{array}{l}\text { Suitable for } \\
\text { freezing }\end{array}$ & $\begin{array}{l}\text { Main detrimental issues during } \\
\text { freezing }\end{array}$ & $\begin{array}{l}\text { Published range of PSLs at } \\
-18^{\circ} \mathrm{C} \text { (months) }\end{array}$ \\
\hline Bread & Good & Yes & Staling, dehydration & 0.5 to 8 \\
\hline \multicolumn{5}{|c|}{ Freeze in air-tight packaging. Freeze when as fresh as possible. Freeze in portions to speed up freezing rate and for ease of use. } \\
\hline \multirow{2}{*}{\multicolumn{5}{|c|}{$\begin{array}{l}\text { Pork (cooked sliced ham, bacon, } \quad \text { Good } \\
\text { raw \& cooked sausage) } \\
\text { For best quality, freeze when fresh. Safe to freeze up to use by date (defrost and use within 24 hours). } \\
\text { Wrap in air-tight packaging. Defrost in fridge. Remove as much fat as possible prior to freezing. }\end{array}$}} \\
\hline & & & & \\
\hline Vegetables & Good & $\begin{array}{r}\text { Generally yes } \\
\text { (if blanched) }\end{array}$ & Loss of flavour, colour, texture & 1 to18 \\
\hline \multicolumn{5}{|c|}{ Some high water content vegetables not suitable for freezing, but many can be chopped and successfully frozen. } \\
\hline \multicolumn{5}{|c|}{ Freeze as soon as possible to retain vitamins/nutrients. Blanching prior to freezing is essential to inactivate enzymes. } \\
\hline \multicolumn{5}{|c|}{ Wrap in air-tight packaging. Freeze in small volumes for best results. Most vegetables can be cooked directly from frozen. } \\
\hline \multicolumn{5}{|c|}{ Individually freeze items if possible as freezing is faster and portioning is simpler, then transfer to bags. } \\
\hline Fruit & Good & Mostly yes & Loss of structure & 4 to 24 \\
\hline \multicolumn{5}{|c|}{$\begin{array}{l}\text { Wrap in air-tight packaging. Freeze as soon after harvest / purchase as possible. Individually freeze fruits if possible to accelerate } \\
\text { freezing rate and reduce loss of structure on thawing, then transfer to bags. Consider making fruits into sauces or purees to freeze, } \\
\text { to save space and to utilise fruits that are likely to lose structure after thawing. }\end{array}$} \\
\hline Pasta meals (home-made) & Limited & Mostly yes & Separation of sauces, texture of pasta & 2 to 4 \\
\hline \multicolumn{5}{|c|}{$\begin{array}{l}\text { Cool rapidly after cooking. Freeze in portions, freeze in air-tight container or bag. If preparing food specifically to freeze, } \\
\text { undercook meal to allow reheating after meal is thawed. Keep thawed product in fridge for up to } 1 \text { day before eating. }\end{array}$} \\
\hline Rice meals (home-made) & Limited & Mostly yes & Bacteria growth prior to freezing & 2 to 4 \\
\hline \multicolumn{5}{|c|}{$\begin{array}{l}\text { Cool rapidly after cooking. Freeze in portions, freeze in air-tight container or bag. If preparing food specifically to freeze, } \\
\text { undercook meal to allow reheating after meal is thawed. Keep thawed product in fridge for up to } 1 \text { day before eating. }\end{array}$} \\
\hline \multirow[t]{2}{*}{ Chilled ready meals } & Very poor & Yes & Separation of sauces, texture of meal & No review data \\
\hline & & & WRAP s & survey found most packs advise 1 \\
\hline \multicolumn{5}{|c|}{ For best quality, freeze when fresh. Safe to freeze up to use by date (defrost and use within $24 \mathrm{~h}$ ). Cook from frozen or defrost in fridge } \\
\hline Milk & Limited & Mostly yes & Separating and curdling & 1 to 4 \\
\hline \multicolumn{5}{|c|}{$\begin{array}{l}\text { For best quality, freeze when fresh. Safe to freeze up to use by date (defrost and use within } 24 \text { hours). Freeze in small quantities if } \\
\text { possible. Leave headspace / decant into suitable container. Thaw in fridge. Shake after thawing to re-combine. }\end{array}$} \\
\hline Store-bought yoghurt & Limited & Mostly yes & Texture and separation & $\begin{array}{l}1 \text { to } 2 \text { plain } \\
\text { Up to } 5 \text { flavoured }\end{array}$ \\
\hline \multicolumn{5}{|c|}{ Freeze as soon as possible after purchase. Freeze in small quantities if possible. Freeze in air-tight container. } \\
\hline \multicolumn{5}{|c|}{ Thaw in fridge. Stir after thawing to re-combine. Consider making yoghurt ice cream or lollies to use up spare yoghurt. } \\
\hline Fruit juice & Limited & Yes & Thickening & 4 to 12 \\
\hline \multicolumn{5}{|c|}{$\begin{array}{l}\text { Freeze as soon as possible after purchase. Pasteurise fresh juices. Freeze in small quantities if possible. Freeze in air-tight container. } \\
\text { Thaw in fridge. Shake after thawing to re-combine. Consider making lollies to use up spare juice. }\end{array}$} \\
\hline Ambient cooking sauces & Very poor & Mostly yes & Separation of sauces, texture of meal & No review data \\
\hline \multicolumn{5}{|c|}{$\begin{array}{l}\text { Freeze unopened sauces as soon as possible after purchase. Decant saucesin glass jars to plastic containers / bags. Once opened, } \\
\text { refrigerate immediately, use / freeze within time indicated on the label. If made into meals, follow guidance for home-cooked meals. }\end{array}$} \\
\hline Meat joints (raw and cooked) & Good & Yes & Rancidity, oxidation & 1 to 12 \\
\hline $\begin{array}{l}\text { Freeze when fresh. Safe to freez } \\
\text { fat as possible prior to freezing. }\end{array}$ & $\begin{array}{l}\text { We up to use by da } \\
\text { Wrap in air-tight }\end{array}$ & $\begin{array}{l}\text { (defrost and } \\
\text { ackaging. Co }\end{array}$ & $\begin{array}{l}\text { vithin } 24 \text { h). Freeze in small portion } \\
\text { nd eat soon after thawing or cook }\end{array}$ & $\begin{array}{l}\text { ns if possible. Remove as much } \\
\text { smaller portions from frozen. }\end{array}$ \\
\hline
\end{tabular}

Table 1. Brief summary of product specific freezing information 


\begin{tabular}{lccc}
\hline Test period (each of 24h duration) & $\begin{array}{c}\text { Run time } \\
(\%)\end{array}$ & $\begin{array}{c}\text { Average } \\
\text { power (W) }\end{array}$ & $\begin{array}{c}\text { Energy } \\
\left(\mathrm{kWh} .24 \mathrm{~h}^{-1}\right)\end{array}$ \\
\hline Stable operation before food added & 30.0 & 24.0 & 0.576 \\
Warm food added during 2 minute door opening & 38.2 & 30.4 & 0.730 \\
Stable operation after food added & 30.2 & 24.2 & 0.581 \\
No food added but 2 minute door opening & 33.3 & 26.6 & 0.638 \\
Stable operation after door opening only & 30.1 & 24.1 & 0.579 \\
\hline
\end{tabular}

Table 2. Refrigeration compressor run-time and average power 


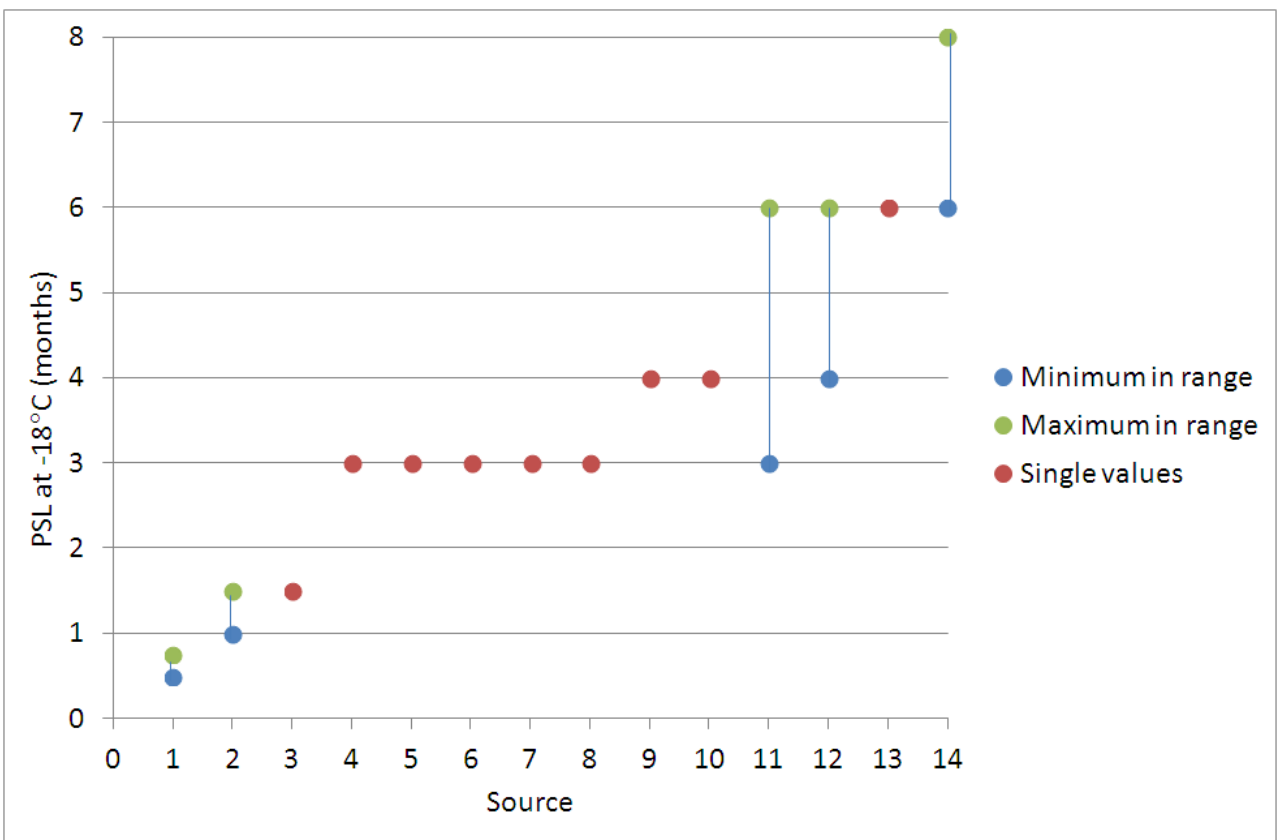

Figure 1. Reported Practical Storage Life (PSL) values for bread stored at $-18^{\circ} \mathrm{C}$ 


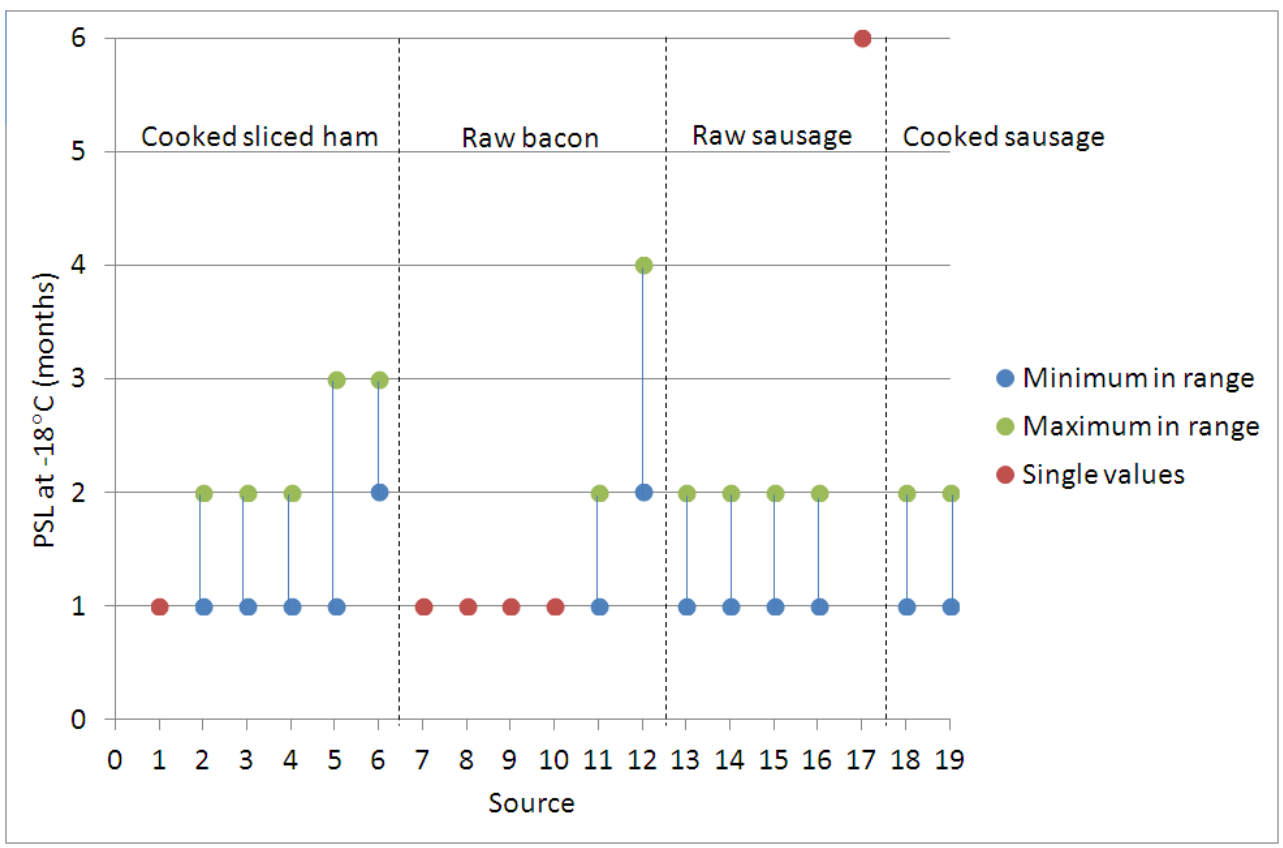

Figure 2. Reported Practical Storage Life (PSL) values for raw and cooked pork products stored at $-18^{\circ} \mathrm{C}$ 


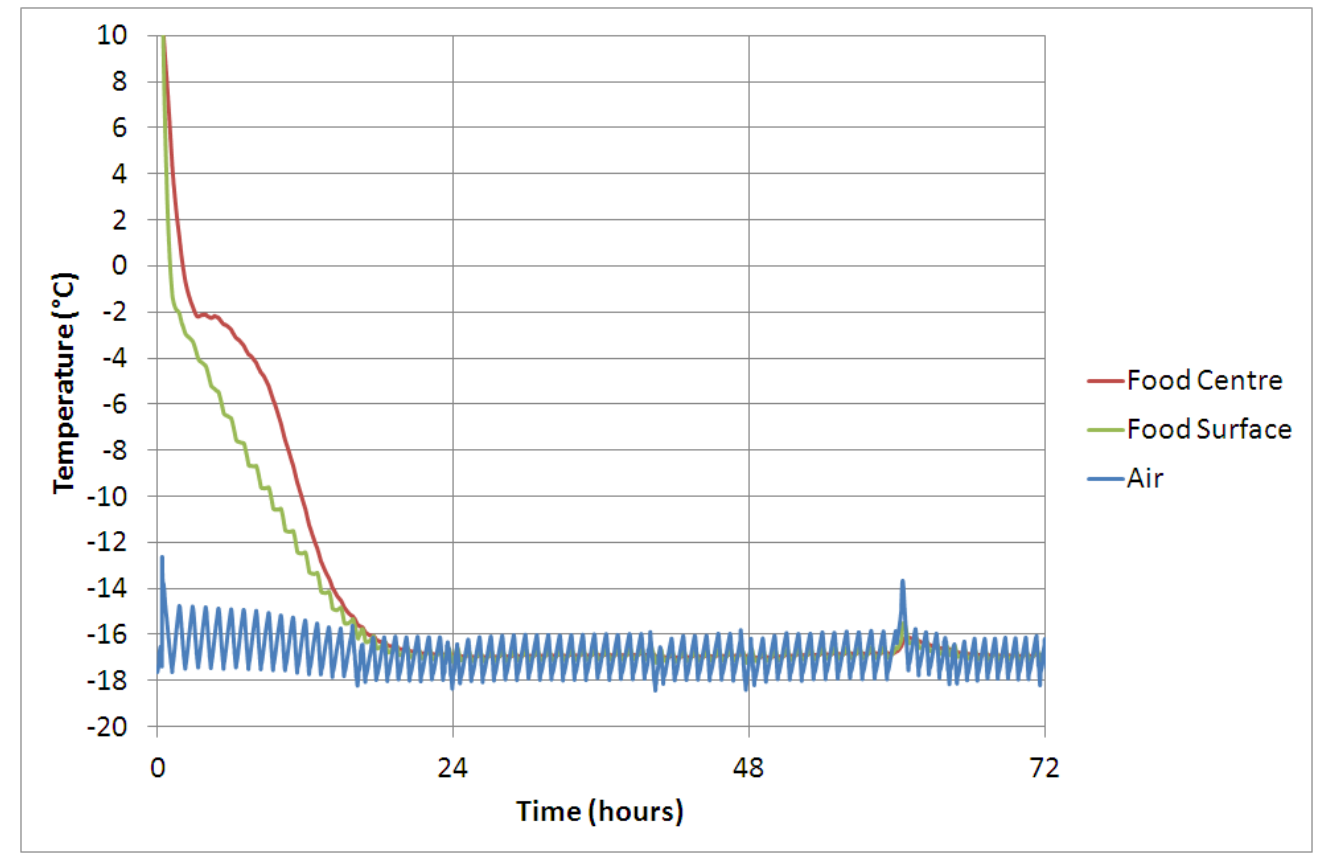

Figure 3. Average air, food centre and food surface temperatures in the freezer (foods added were lasagne, bread, chicken and cottage pie as detailed in Section 2.2.). 